\title{
Desconforto térmico durante a estação seca em uma cidade de Clima Tropical Chuvoso na Amazônia
}

A avaliação da sensação térmica em Santarém é importante, devido à recente expansão física e populacional da cidade. Santarém é a terceira maior cidade do Pará, tanto em tamanho, quanto em população. O clima Equatorial, caracterizado com temperatura do ar e umidade relativa do ar elevadas ao longo do ano, associado a variações diurnas de temperatura, mesmo que pequenas, podem representar alterações importantes no conforto/desconforto térmico do ambiente urbano. Neste sentido, o conforto térmico horário foi testado por meio de quatro modelos capazes de retorna a resposta térmica local, focados neste estudo na estação seca de 2016 (julho a novembro), utilizando dados da estação meteorológica automática de superfície de Santarém. Entre os resultados encontrados podemos destacar que, no intervalo de 11 às $18 \mathrm{~h}$, em ambiente aberto, a sensação térmica varia de desconfortável a extremante desconfortável. Entre 14 e $17 \mathrm{~h}$, os índices apontam sensação muito quente com falha na termorregulação do corpo e cautela extrema, estas sensações térmicas estão associadas aos valores máximos de temperatura ar em torno de $31^{\circ} \mathrm{C}$ e umidade relativa inferior a $60 \%$. A compreensão acerca da sensação térmica atual em Santarém e dos horários mais críticos, servem como subsidio para medidas de prevenção a exposição a ambientes abertos, além de possibilidade de emissão de alertas a sociedade e poder público.

Palavras-chave: Sensação térmica; Santarém; Clima urbano.

\section{Thermal discomfort during the dry season in a tropical rainy city in the Amazon}

\begin{abstract}
The assessment of thermal sensation in Santarém is important due to the recent physical and population expansion of the city. Santarém is the third largest city in Pará, both in size and population. The Equatorial climate, characterized by high air temperature and relative humidity throughout the year, associated with daytime temperature variations, even small, may represent important changes in the thermal comfort / discomfort of the urban environment. In this sense, the hourly thermal comfort was tested through four models capable of returning the local thermal response, focused in this study in the dry season of 2016 (July to November), using data from the Santarém automatic surface weather station. Among the results we can highlight that, in the interval from 11 am to $6 \mathrm{pm}$, in an open environment, the thermal sensation varies from uncomfortable to extremely uncomfortable. Between 14 and $17 \mathrm{~h}$, the indices indicate very hot sensation with body thermoregulation failure and extreme caution, these thermal sensations are associated with the maximum air temperature around $31^{\circ} \mathrm{C}$ and relative humidity below $60 \%$. Understanding about the current thermal sensation in Santarém and the most critical hours, serve as a subsidy for measures to prevent exposure to open environments, as well as the possibility of issuing warnings to society and the public authorities.
\end{abstract}

Keywords: Thermal sensation; Santarém; Urban climate.

Topic: Meteorologia, Climatologia e Mudanças Climáticas

Reviewed anonymously in the process of blind peer
Received: $16 / 08 / 2018$

Approved: 22/08/2018
Gedinara Paiva dos Santos

Universidade Federal do Oeste Pará, Brasil

http://lattes.cnpq.br/3313094495956562

narapaivasantos@gmail.com

Leidiane Leão Oliveira

Universidade Federal do Oeste do Pará, Brasil

http://lattes.cnpq.br/5016148560650320

leidianeoli@gmail.com

Joseandra Aparecida Campos da Silva (it)

Universidade Federal do Oeste do Pará, Brasil

http://lattes.cnpq.br/5432643951755423

http://orcid.org/0000-0001-9947-9557

joseandracampos@gmail.com

\author{
Naurinete de Jesus da Costa Barreto (iD \\ Universidade Federal do Rio Grande do Norte \\ http://lattes.cnpq.br/9415435965900811 \\ http://orcid.org/0000-0002-2691-6020 \\ netebarreto@gmail.com \\ Rodolfo Maduro Almeida (iD) \\ Universidade Federal do Oeste do Pará, Brasil \\ http://lattes.cnpq.br/1527651015984510 \\ http://orcid.org/0000-0003-4564-825X \\ rodolfomaduroalmeida@gmail.com
}

Referencing this:

SANTOS, G. P.; OLIVEIRA, L. L.; SILVA, J. A. C.; BARRETO, N. J. C.; ALMEIDA, R. M.. Desconforto térmico durante a estação seca em uma cidade de Clima Tropical Chuvoso na Amazônia. Revista IberoAmericana de Ciências Ambientais, v.9, n.6, p.169-179, 2018. DOI: http://doi.org/10.6008/CBPC2179-6858.2018.006.0018 


\section{INTRODUÇÃO}

No Brasil, a expansão de áreas urbanas é agravada pela falta de planejamento. Fato que compromete a qualidade ambiental em nossas cidades, algo evidenciado em cidades na Amazônia. Segundo os dados do IBGE, o estado do Pará é uma das regiões do Brasil com as maiores taxas de crescimento populacional. Neste sentido, Santarém desponta como o terceiro município mais populoso do Pará, ocasionando a expansão urbana de forma desordenada, gerando alterações no microclima local (ALMEIDA, 2006; COSTA et al., 2016; BARBOSA et al., 2015), sendo este crescimento o principal fator destas alterações, e com o aumento das necessidades humanas, o homem altera o seu meio natural modificando também as suas sensações perante este meio tornando muitas vezes mais desconfortáveis. A expansão das áreas urbanas é frequentemente associada a mudanças no clima local (ALMEIDA, 2006; RIZWAN et al., 2008; MEMON et al., 2008).

A alteração na cobertura natural do solo e o incremento de massa edificada, dentre outros fatores, criam um clima peculiar denominado "clima urbano" (GARTLAND, 2011). A ocupação desordenada do solo, o adensamento da população urbana, o grande aumento de construções, a substituição da vegetação natural e propriedades térmicas dos materiais artificiais que compõem o ambiente urbano, são variáveis envolvidas na alteração do balanço energético local, e consequentemente ocasionando vários problemas, como o desconforto térmico e a formação de ilha de calor urbana, fatores mais visíveis no verão (OLIVEIRA et al., 2011; MEMON et al., 2008; BARBOSA et al., 2015).

As cidades têm uma atmosfera mais instável o que ocasiona diminuição na velocidade do vento em relação ao campo (ALMEIDA, 2006). Assim, a tendência do ar, sob condições atmosféricas estáveis, é circular do campo: menos quente, alta pressão - em direção ao centro; mais quente, baixa pressão (AMORIM, 2005; UCHÔA, 2011). Em estudo realizado em 2009 em Santarém, constatou-se o fenômeno de ilha de calor urbana, com máxima intensidade, $4,7^{\circ} \mathrm{C}$ no período noturno, em locais densamente urbanizados (UCHÔA, 2011).

Estudos que investiguem o clima urbano devem ser difundidos, considerando que em 2009 se identificou ilhas de calor com intensidade máxima no município de Santarém. O crescimento urbano acelerado que vem ocorrendo, baseado em estudos detalhados sobre as características climáticas locais, são necessários, com avaliações focadas na variação horária das sensações térmicas, meses de ocorrência e características sazonais, pois tais condições associadas a eventos climáticos de grande escala como as secas de 2015 e 2016, podem afetar severamente a população e a qualidade de vida nos centros urbanos.

O objetivo principal deste estudo é caracterizar a sensação térmica horária local cidade de Santarém para o período de julho a novembro de 2016. Dentre as contribuições deste trabalho, buscamos entender melhor a relação combinada das variáveis climáticas locais (vento, radiação solar, temperatura e umidade relativa do ar) com a diferentes respostas térmicas, além de testada diversos modelos, buscando gerar resultados que podem ser aplicados como ferramentas para prever as condições de conforto térmico local. 


\section{MATERIAIS E MÉTODOS}

O estudo foi desenvolvido no munícipio de Santarém, no Oeste do estado do Pará, localizado no Norte do Brasil, com latitude $02^{\circ} 26^{\prime} 35^{\prime \prime}$ S e longitude $54^{\circ} 42^{\prime} 30^{\prime \prime} \mathrm{W}$, altitude de 51 metros e uma área de 24422,5 km² (IBGE, 2017) (figura 1). O município apresenta clima tropical úmido, com variação térmica anual inferior a $5^{\circ} \mathrm{C}$ e precipitação média anual em torno de $1820 \mathrm{~mm}$ (classe Ami, conforme sistema Köppen). Ao contrário da temperatura, o regime de chuvas apresenta grande variação durante o ano, com o maior volume de precipitações ocorrendo nos meses de janeiro a maio. A vegetação de terra firme mais frequente é a Floresta Ombrófila Densa, vegetação dominante no norte do país e que abrange a maior parte dos estados do Pará, Amazonas, Amapá e Roraima (IBAMA, 2004).

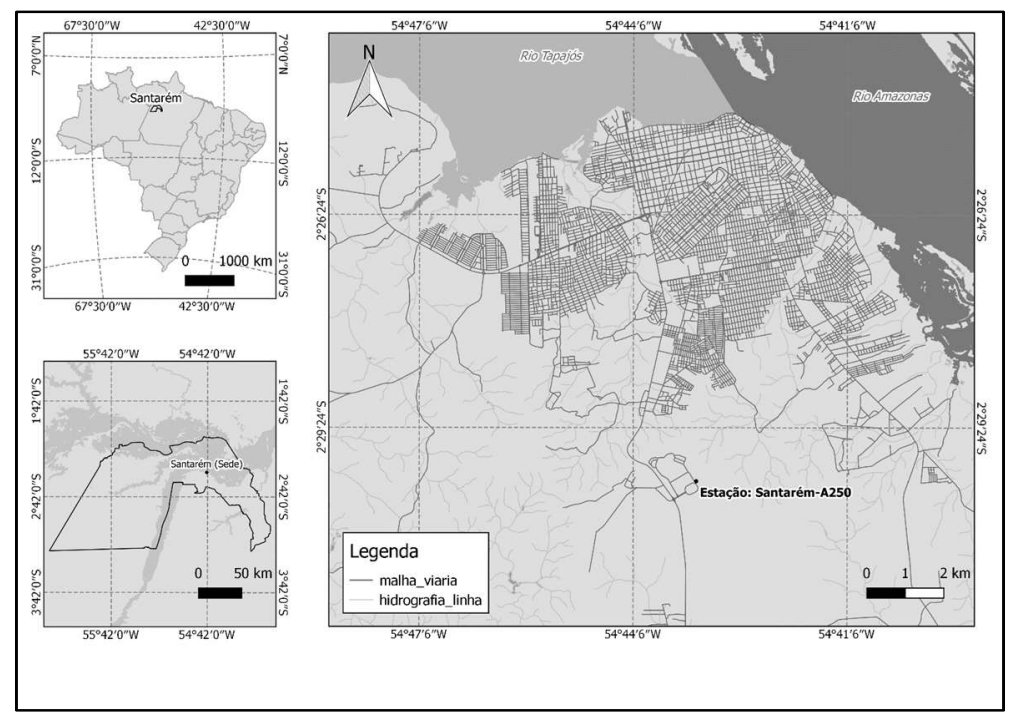

Figura 1: Localização geográfica da área de estudo, cidade de Santarém, Pará. Localização da estação meteorológica automática de Santarém - A250.

Os dados foram obtidos na estação meteorológica automática de Santarém - A250 localizada a $2.502572^{\circ}$ de latitude e $-54.720279^{\circ}$ de longitude e a 137 metros de altitude, conforme se ilustra na figura 1. A estação meteorológica está situada no 8 Batalhão de Engenharia e Construção de Santarém e é administrada pelo Instituto Nacional de Meteorologia.

Para o desenvolvimento deste estudo, foram necessários os dados de temperatura do $\operatorname{ar}\left({ }^{\circ} \mathrm{C}\right)$, mínima $\left({ }^{\circ} \mathrm{C}\right)$ e máxima $\left({ }^{\circ} \mathrm{C}\right)$, umidade relativa do ar $(\%)$, mínima (\%) e máxima $(\%)$, radiação solar $\left(\mathrm{kJ} / \mathrm{m}^{2}\right)$, velocidade do vento $(\mathrm{m} / \mathrm{s})$ e precipitação pluvial $(\mathrm{mm})$ durante o período de julho a novembro de 2016 , que corresponde ao período menos chuvoso da região. Para determinar o conforto térmico foram utilizados os seguintes índices, Índice de Temperatura e Umidade - ITU, Índice de Temperatura e Umidade modificado - ITUm, Índice de Temperatura Efetiva em função do vento - TEv, Índice de Calor - IC, todos foram avaliados de forma horária.

O Índice de Temperatura e Umidade (ITU), foi desenvolvido por Thom, em 1959, devido à simplicidade é o mais utilizado nas regiões equatoriais, pois são necessários apenas os dados de temperatura e umidade relativa do ar aplicados na equação $\mathrm{ITU}=[\mathrm{T}-0,55 *(1-0,01 * \mathrm{UR}) *(\mathrm{~T}-14,5)]$, onde: ITU=Índice de Temperatura e Umidade $\left({ }^{\circ} \mathrm{C}\right) ; \mathrm{T}=$ Temperatura do $\operatorname{ar}\left({ }^{\circ} \mathrm{C}\right)$; e UR=Umidade relativa do ar $(\%)$. 
Depois de calculado o valor do ITU, é verificada a faixa de conforto que se enquadra, admite como zona de conforto os valores definidos por Thom e adaptados por Diniz Júnior (2013) para Santarém (PA), conforme se vê tabela 1.

Tabela 1: Sensação de conforto térmico do corpo relacionado com o ITU, adaptado por Diniz Júnior (2012).

\begin{tabular}{|l|l|}
\hline FAIXA - ITU $\left({ }^{\circ} \mathbf{C}\right)$ & DESCONFORTO \\
\hline 29 & Estresse \\
\hline $27-29$ & Muito desconfortável \\
\hline $24-27$ & Desconfortável \\
\hline $21-24$ & Confortável \\
\hline
\end{tabular}

A faixa de conforto definida por Thom e adaptada por Diniz Júnior (2013) considera como pouco desconfortável o intervalo entre 21 a $24^{\circ} \mathrm{C}$. Valores acima de $29^{\circ} \mathrm{C}$ correspondem a sensações estresse térmico e entre 27 a $29^{\circ} \mathrm{C}$ muito desconfortável e desconfortável valores entre 24 a $27^{\circ} \mathrm{C}$. Em cada faixa de Temperatura Efetiva é possível observar as consequências sobre a população estudada.

O Índice de Temperatura e Umidade modificado $\left(I T U_{m}\right)$, este índice é um dos índices utilizados para ambientes abertos, já que permite quantificar o "stress" no ambiente urbano. Foi utilizado por Nóbrega et al. (2011) para a cidade de Recife (PE), que evidenciou a sua aplicabilidade em regiões tropicais e a praticidade em sua aplicação. É descrito como $I T U_{m}=\left[0,8 * T+\left(\frac{U R * T}{500}\right)\right.$, onde $\operatorname{ITU}_{\mathrm{m}}$ é o índice de temperatura e umidade modificado $\left({ }^{\circ} \mathrm{C}\right)$; T é a temperatura do $\operatorname{ar}\left({ }^{\circ} \mathrm{C}\right)$; e UR é umidade relativa do ar (\%). Os critérios de classificação para este índice podem ser observados na tabela 2.

Tabela 2: Faixa de conforto térmico baseado no índice de temperatura e umidade modificado.

\begin{tabular}{|c|c|}
\hline $\boldsymbol{I T U _ { m }}\left({ }^{\circ} \mathrm{C}\right)$ & NÍVEL DE CONFORTO \\
\hline$>26^{\circ} \mathrm{C}$ & Extremamente desconfortável \\
\hline $24-26{ }^{\circ} \mathrm{C}$ & Levemente desconfortável \\
\hline $21-24{ }^{\circ} \mathrm{C}$ & Confortável \\
\hline
\end{tabular}

O índice Temperatura Efetiva em Função do Vento (TEv) foi derivado do Índice de Temperatura Efetiva, leva em consideração a variável velocidade do vento. Foi desenvolvido pelo laboratório de Meteorologia Aplicada a Sistemas de Tempo Regionais (MASTER - IAG/USP), usada para prever as condições de conforto térmico no Sul, Sudeste e Centro-Oeste do Brasil, conforme Sousa et al. (2012).

Neste estudo, escolhemos utilizar este índice para testar localmente, pois entendemos que a velocidade do vento influencia no conforto térmico local, por exemplo, o efeito dos ventos locais, tais como, a brisa fluvial do Rio Tapajós e Amazonas. A equação para o cálculo do conforto térmico obtida pelo Índice de Temperatura e Umidade em função do vento - TEv é descrita por TEv $=37-\frac{37-T}{0,68-0,001 * U R+\frac{1}{1,7+1,4 * V * 0,75}}-$ $0,29 * T *\left(1-\frac{U R}{100}\right)$, onde TEv é Temperatura Efetiva em função do vento $\left({ }^{\circ} \mathrm{C}\right)$; T é a temperatura do $\operatorname{ar}\left({ }^{\circ} \mathrm{C}\right)$; UR é a umidade relativa (\%); e V é a velocidade do vento $(\mathrm{m} / \mathrm{s})$, de acordo com o laboratório MASTER (IAG/USP).

Tabela 3. Classificação da Temperatura Efetiva, segundo o laboratório de Meteorologia Aplicada a Sistemas de Tempo Regionais (MASTER - IAG/USP).

\begin{tabular}{|c|c|c|}
\hline $\mathbf{z}$ & Sensação Térmica & Grau de estresse fisiológico \\
\hline $22-25$ & Confortável Neutralidade térmica & Confortável Neutralidade térmica \\
\hline
\end{tabular}




\begin{tabular}{|l|c|c|}
\hline $25-28$ & Ligeiramente Quente Ligeiro suor; vasodilatação & Ligeiramente Quente Ligeiro suor; vasodilatação \\
\hline $28-31$ & Quente Moderado Suando & Quente Moderado Suando \\
\hline $31-34$ & Quente Suor em profusão & Quente Suor em profusão \\
\hline$>34$ & Muito Quente Falha na termorregulação & Muito Quente Falha na termorregulação \\
\hline
\end{tabular}

Fonte: Sousa et al. (2012).

Segundo Sousa et al. (2012), o laboratório MASTER considera como termicamente confortável o intervalo entre 22 a $25^{\circ} \mathrm{C}$. Valores abaixo de $22{ }^{\circ} \mathrm{C}$ correspondem a sensações que variam de ligeiramente fresco a muito frio e acima de $25^{\circ} \mathrm{C}$ variam de ligeiramente quente a muito quente. Em cada faixa de Temperatura Efetiva é possível observar as consequências sobre a população estudada.

O Índice de calor (Heat Index) é utilizado pelo Serviço Nacional de Meteorologia dos EUA (NOAA, na sigla em inglês) disponibiliza em seu site uma calculadora, onde se insere a temperatura e a umidade do ar para se obter a sensação térmica. O índice de calor é utilizado na previsão do tempo e alertas de risco de ondas de calor pelo serviço de tempo americano (US National Weather Service - NWS). Optou-se pela utilização deste índice de calor, pois na cidade de Santarém (PA) os valores de temperatura e umidade relativa do ar são elevados durante o ano inteiro. Sendo assim, as altas temperaturas favorecem a transpiração e os altos valores de umidade dificultam a perda de calor por meio da evaporação.

O cálculo do índice de calor é calculado para temperaturas superiores a $20^{\circ} \mathrm{C}$, à sombra e com ventos fracos é dada pela equação proposta. Em seguida, podem ser observado os níveis de alerta e as consequências para o ser humano, conforme a tabela 4. Tem-se a equação $I C=-42,379+$ $(2,0490152 * T)+(10,1433312 * U R)-\left(0,006837 * T^{2}\right)-0,05481717 * U R^{2}+\left(0,0012287 * T^{2} *\right.$ $\left.U R)-\left(0,00000199 * T^{2} * U R^{2}\right)\right)$, onde IC é o índice de calor $\left({ }^{\circ} \mathrm{F}\right)$; T é a temperatura do $\operatorname{ar}\left({ }^{\circ} \mathrm{C}\right)$; e UR é a umidade relativa do ar (\%). Em seguida, converte-se o resultado da IC para $\left({ }^{\circ} \mathrm{C}\right)$, utilizando-se $\mathrm{T}_{\mathrm{C}}=\frac{5}{9} *$ $\left(\mathrm{T}_{\mathrm{f}}-32\right)$, na qual $\mathrm{T}_{\mathrm{C}}$ é a temperatura $\left({ }^{\circ} \mathrm{C}\right)$; e $\mathrm{T}_{\mathrm{F}}$ é a temperatura $\left({ }^{\circ} \mathrm{F}\right)$.

Tabela 4: Níveis de alerta do índice de calor e suas consequências à saúde humana.

\begin{tabular}{|c|c|l|}
\hline $\begin{array}{c}\text { Nível de } \\
\text { Alerta }\end{array}$ & $\begin{array}{c}\text { Índice de } \\
\text { Calor }\left({ }^{\circ} \mathrm{C}\right)\end{array}$ & \multicolumn{1}{|c|}{ Síndrome de Calor (sintomas) } \\
\hline $\begin{array}{c}\text { Perigo } \\
\text { extremo }\end{array}$ & $>54$ & Insolação ou ação e risco de Acidente Vascular Cerebral (AVC) iminente \\
\hline Perigo & $41,1-54$ & $\begin{array}{l}\text { Câimbras, insolação e provável esgotamento. Possibilidade de dano cerebral (AVC) para } \\
\text { exposições prolongadas com atividades físicas. }\end{array}$ \\
\hline $\begin{array}{c}\text { Cautela } \\
\text { extrema }\end{array}$ & $32,1-41$ & $\begin{array}{l}\text { Possibilidade de câimbras, esgotamento e insolação para exposições prolongadas e atividade } \\
\text { física. }\end{array}$ \\
\hline Cautela & $27,1-32$ & $\begin{array}{l}\text { Possível fadiga em casos de exposição prolongada e atividade física. Não há alerta menor que } \\
27^{\circ} \text { C não há problemas }\end{array}$ \\
\hline
\end{tabular}

Fonte: Nóbrega et al. (2011).

A caracterização dos padrões horários das variáveis meteorológicas estudadas serve como embasamento para as avaliações a respeito das características térmicas da cidade de Santarém, visto que os índices calculados neste estudo utilizam como base as variáveis meteorológicas. Neste caso foi utilizado gráficos de 'boxplot', que expressam de forma concisa a variação dentro de um determinado horário e a variabilidade ao longo do dia. O que torna uma ferramenta muito útil, já que é possível avaliar de forma simplificada: mínimo, máximo, quantis e a mediana. As análises e saídas gráficas foram geradas no ambiente estatístico R Core Team. 


\section{RESULTADOS}

\section{Índices de Conforto Térmico}

Encontrou-se as seguintes sensações térmicas horárias, muito desconfortável (12 às 17h), desconfortável ( 8 às $11 \mathrm{~h}$ e 18 às $2 \mathrm{~h}$ ) e confortável ( 4 às $6 \mathrm{~h}$ ), conforme se pode ver na figura 2a. 0 ITUmodificado apresentou sensação térmica extremamente desconfortável (10 às 19h), levemente desconfortável (20 às $3 \mathrm{~h}$ e 7 às $11 \mathrm{~h}$ ) e confortável (4 às $6 \mathrm{~h}$ ) (figura 2b). Na análise dos resultados do ITU em função do vento encontrou-se sensação térmica de extremamente quente (14 às 19h), muito quente (20 às $5 \mathrm{~h}, 12$ às $13 \mathrm{~h}$ ) e quente moderado (6 às 11h) (figura 2c). O IC apresentou sensação térmica dentro do intervalo de cautela extrema (11 às $18 \mathrm{~h}$ ), cautela ( 8 às $10 \mathrm{~h}$ e 19 às $23 \mathrm{~h}$ ) e confortável ( 0 às $7 \mathrm{~h}$ ) (figura $2 \mathrm{~d}$ ).

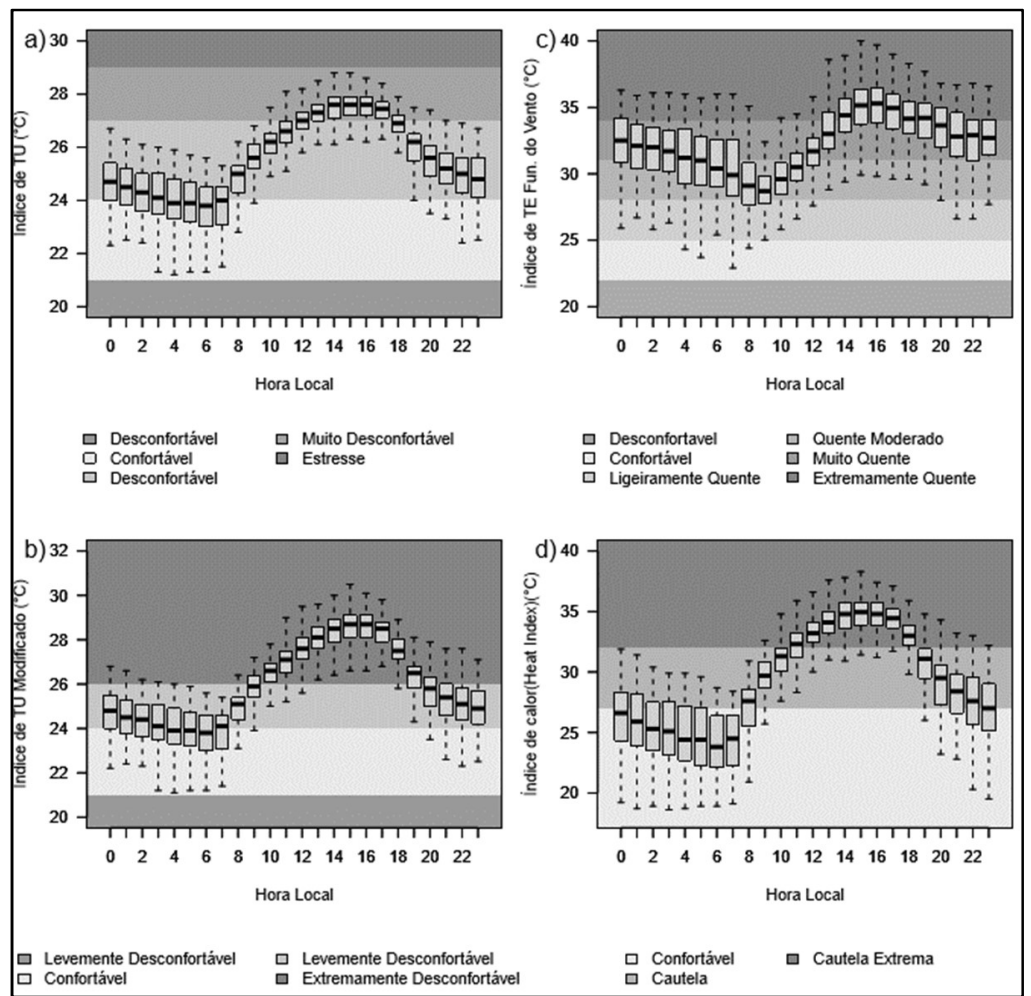

Figura 2: Testes comparativos dos índices de conforto térmico em relação a variação horária local para a estação seca (julho a novembro) do ano de 2016 para Santarém-PA. a) Índice de temperatura e umidade; b) Índice de temperatura e umidade modificado; c) Índice de temperatura efetiva em função do vento; d) Índice de Calor (Heat Index).

Nos horários de 10 às $18 \mathrm{~h}$ foram identificadas as sensações extremas de desconforto térmico. Notase que tem relação com o intervalo dos maiores registros de radiação solar, onde atinge seu pico máximo às $14 \mathrm{~h}$ com média de $2989 \mathrm{~kJ} / \mathrm{m}^{2}$. A partir das $14 \mathrm{~h}$ ocorre um decréscimo nos valores de radiação solar, onde passa a registrar radiação negativa a partir das $20 \mathrm{~h}$, durante o restante das horas noturnas a radiação apresenta-se com valores negativos até as $6 \mathrm{~h}$ onde ocorrem os primeiros registros de radiação solar diária (figura 3).

Também, nota-se que as sensações de desconforto registradas em todos os índices analisados, têm relação com o intervalo de variação dos valores de radiação solar, que aquece a superfície, consequentemente, aquece o ar próximo à superfície, onde a temperatura do ar eleva-se, atingindo seu pico as 15 e $16 \mathrm{~h}\left(31,1^{\circ} \mathrm{C}\right)$, diminuindo durante o restante do dia (figura $\left.4 \mathrm{a}\right)$. Nota-se que a temperatura do ar se 
mantém sempre acima de $27^{\circ} \mathrm{C}$ no intervalo de 10 às $19 \mathrm{~h}$, mesmo horário do registro dos piores graus de desconforto.

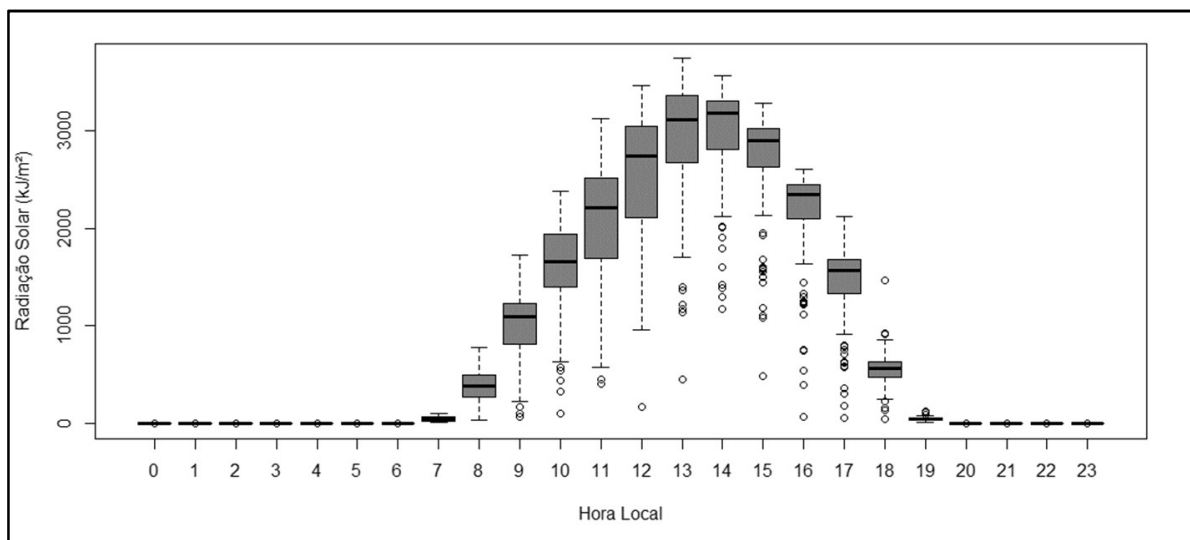

Figura 3: Radiação Solar horária durante o período de julho a novembro de 2016 para o município de Santarém (PA).

Nota-se que a umidade relativa do ar diminui com o aumento da temperatura do ar, e atinge seu mínimo entre 15 e $16 \mathrm{~h}(56 \%)$ e os maiores valores entre 5 e $6 \mathrm{~h}(89 \%)$ tendendo a diminuir durante o restante da manhã e pela tarde e aumentando a partir das 18h (figura 4b). Podemos inferir que as piores sensações térmicas estão relacionadas aos intervalos de horas em que temos os maiores registros de radiação solar, temperatura do ar e os menores valores de umidade do ar.

$\mathrm{O}$ contraponto é que os maiores registros da velocidade do vento ocorrem no intervalo de 9 às $18 \mathrm{~h}$, com máximo registrado às $12 \mathrm{~h}(2,50 \mathrm{~m} / \mathrm{s})$. Isto pode ser justificado que este horário é onde apresenta o maior contraste térmico de aquecimento entre duas áreas, por exemplo, entre o Rio Tapajós e a cidade de Santarém, ou contraste térmico entre áreas rurais ou vegetadas e a área urbana (figura 4c).

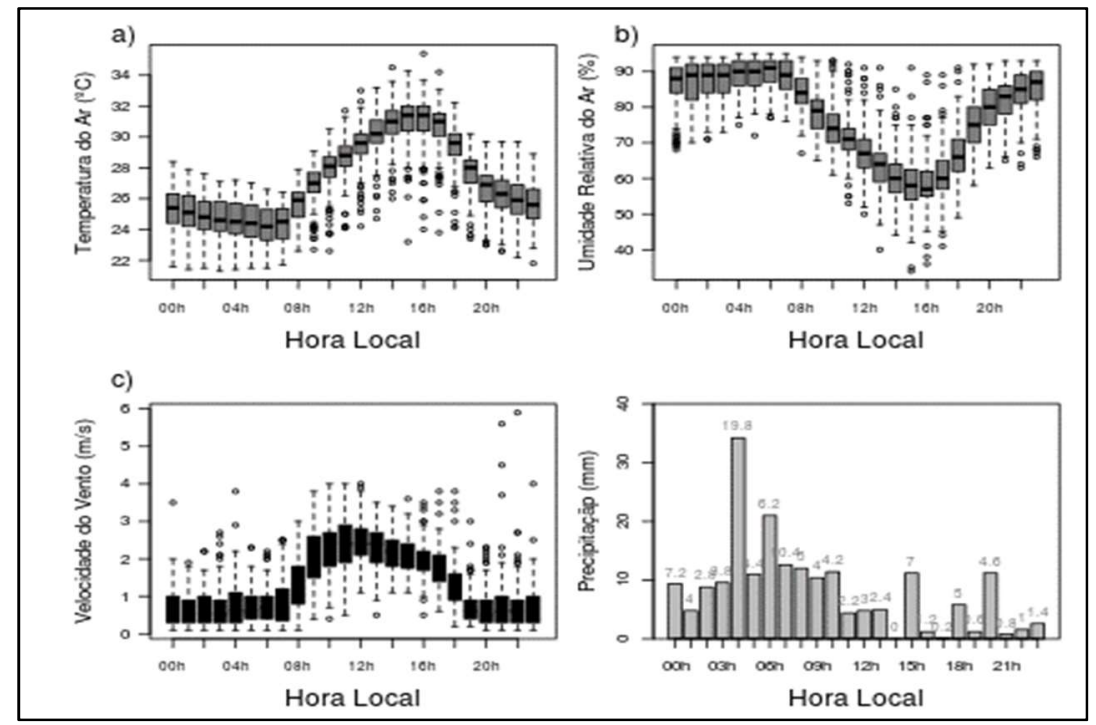

Figura 4. Testes comparativos dos elementos meteorológicos em relação a variação horária local para a estação seca (julho a novembro) do ano de 2016 para Santarém (PA). a) Temperatura do ar; b); Umidade relativa do ar; c) velocidade do vento; d) Precipitação pluvial.

A variação horária da velocidade do vento se deve a brisa Rio-Terra gerada pela diferença de calor específico entre ambos. Durante o dia, a terra aquece-se mais rapidamente que a água, e o ar, ao mover-se 
de uma região mais fria para uma mais quente tende a gerar uma brisa do rio em direção a terra, propiciando a velocidades vento de maior intensidade durante o dia.

Já à noite, o processo se inverte, visto que a água se resfria mais lentamente do que a terra, logo a circulação gerar será terra em direção ao rio, reduzindo a velocidade do vento (FROTA et al., 2001). Santarém apresenta o modelo climático marítimo, cujas precipitações pluviais/trovoadas ocorrem durante a noite, observou-se que raramente precipitações pluviais/trovoadas ocorrem durante o dia, independente da época do ano, havendo uma redução na porcentagem durante a época seca (NECHET et al., 2006). Com relação à precipitação pluvial que poderia amenizar a sensação térmica, podemos observar que durante os meses do verão amazônico apresentou maior valor durante a madrugada às $4 \mathrm{~h}$ com valores abaixo de $20 \mathrm{~mm}$ (figura 4d).

\section{DISCUSSÃO}

Os resultados encontrados neste estudo foram semelhantes ao obtidos por Costa (2013), ou seja, os menores índices horários são registrados entre 6 e 7h, e os maiores valores para este índice aproximadamente às $14 \mathrm{~h}$ tendendo em seguida a diminuir os valores; comparando com outras cidades Amazônicas, Belém e Manaus. Em Belém, os valores mínimos do índice de calor são registrados aproximadamente as $7 \mathrm{~h}$ apresentando seus maiores valores em torno das $13 \mathrm{~h}$, e tendendo ao decaimento de valores após esse horário, e em Manaus, os índices de calor seguem a mesma tendência de menores valores registrados em torno das $7 \mathrm{~h}$ e maiores índices registrados entre 13 e $14 \mathrm{~h}$.

Conforme Silva Júnior et al. (2011), os menores valores registrados de Temperatura Efetiva em Função do Vento - TEV para a cidade de Belém (PA) foram registrados entre as 7 e 8h, apresentando aumento dos valores após esse horário onde seus picos de maiores valores de TEV são registrados em torno das 14 e 15h, decaindo os valores após isso, reforçando assim os dados deste estudo.

Sousa et al. (2010) também corrobora ao apresentar seus resultados de temperatura efetiva para as cidade de Santarém e Belém, onde em Santarém durante o mês de novembro de 2009 (último mês na caracterização do período seco) os menores valores de temperatura efetiva foram registrados entre 7 às $9 \mathrm{~h}$, apresentando progressão de valores após esse horário e os maiores valores para temperatura efetiva foram registrados aproximadamente às 17h; seguindo da semelhança de resultados, Uchôa (2011) também, revalida tais dados ao demonstrar para cidade de Santarém dados de temperatura efetiva onde seus menores valores parte das $7 \mathrm{~h}$, apresentam maiores valores aproximadamente entre as 16 às $17 \mathrm{~h}$ e os valores decaem a partir de tais horários.

A sensação térmica para a cidade de Belém também apresentou valores semelhantes a Santarém, conforme Silva Júnior et al. (2011), ou seja, as $7 \mathrm{~h}$ apresenta valores aproximados a $28^{\circ} \mathrm{C}$ de sensação térmica e picos máximos de valores aproximados de $30^{\circ} \mathrm{C}$ entre as $16 \mathrm{~h}$ e $17 \mathrm{~h}$, Uchôa (2011) também corrobora ao apresentar dados com valores semelhantes para a cidade de Santarém, em que seus menores valores para o Índice de Calor são registados próximo às $6 \mathrm{~h}$ e seus maiores valores entre $14 \mathrm{~h}$ e $16 \mathrm{~h}$ atingindo aproximadamente $34,9^{\circ} \mathrm{C}$. 
Os índices de conforto térmico do atual estudo apresentaram resultados que tendem um padrão similar onde, Índice de Calor (IC), Índice de Temperatura e Umidade modificado (ITUm) e Índice de Temperatura e Umidade (ITU) aproximadamente entre 6h e 7h são registrados os menores valores para estes índices, sendo então um horário que apresenta maior conforto térmico em relação aos demais horários, para a Temperatura Efetiva em Função do Vento (TEv) às 9h apresentou-se os menores valores para este índice. Os picos de maiores valores para TEv e IC são aproximadamente entre 15h e 16h e para ITUm e ITU também entre $15 \mathrm{~h}$ e $16 \mathrm{~h}$, com valores mais baixos após período, todos os índices apresentaram queda de valores durante a noite e madrugada.

As sensações térmicas apresentada apontam como horários mais confortáveis termicamente nas primeiras horas de raios solares durante o dia, entre $6 \mathrm{~h}$ e $7 \mathrm{~h}$ para IC, ITUm, e ITU e aproximadamente às $9 \mathrm{~h}$ para TEv, os valores dos índices acentuam-se após esses horários aumentando assim o desconforto térmico, sendo o pico deste apresentado entre as $15 \mathrm{~h}$ e $16 \mathrm{~h}$ para IC, TEv, ITUm e ITU, sendo esses os horários de sensação térmica menos agradável, durante o fim de tarde e noite todos os índices apresentam baixa de valores apresentando sensações térmicas menos desagradáveis, porém, a maioria dos valores apresentamse acima de $24^{\circ} \mathrm{C}$, faixa essa descrita como desconfortável por Thom, com exceção dos dados de ITUm e ITU entre 5 às $7 \mathrm{~h}$ que apresentam valores aproximados a $23,8^{\circ} \mathrm{C}$ descrito como confortável.

A ITU e ITU modificado evidenciaram resultados similares com sensação térmica de muito desconfortável (13 às 17h) e extremamente desconfortável (11 às 18h). Na análise do TEv, observa-se que a sensação térmica extremamente quente ocorreu no intervalo de 14 às $19 \mathrm{~h}$, porém, o IC evidenciou sensação térmica de cautela extrema de 11 às $18 \mathrm{~h}$.

Assim, de maneira geral, o desconforto térmico registrado no intervalo de 14 às $17 \mathrm{~h}$ em Santarém, com nível de alerta de cautela do índice de calor, pode apresentar como sintomas, possível fadiga em caso de exposição prolongada e realização de atividades físicas. Já no horário de cautela extrema, podem ocorrer sintomas, tais como: câimbras, esgotamento e insolação no caso de exposições prolongadas e realização de atividades físicas. Na análise utilizando o TEv verificou-se que entre as 14 e $18 \mathrm{~h}$ existe sensação térmica maior que $34^{\circ} \mathrm{C}$, que é classificada como muito quente, causando falha na termorregulação, e com isso, estresse fisiológico como sintoma.

Evidenciamos que na cidade de Santarém, durante o período seco (menor precipitação pluvial), sobretudo no intervalo de 11 às $18 \mathrm{~h}$ os resultados indicam que existe um grau de desconforto térmico e estes podem gerar sintomas nocivos à saúde humana. Sabendo-se que o conforto térmico tem relação com fatores externos aos climáticos, tais como: fatores fisiológicos, vestimenta e estado de saúde, somados, estes não foram analisados aqui, evidenciamos que futuros estudos abordem a relação da percepção térmica (sensação subjetiva) com as sensações térmicas obtidas por índices que utilizem dados climáticos, como os obtidos neste estudo, que este estudo seja o início para discussão acerca do conforto térmico e a relação com à saúde humana local.

Neste estudo, os dados climáticos são referentes à estação meteorológica localizada na área rural da cidade e com maior altitude, comparada ao aglomerado urbano, mesmo assim, evidenciamos o grau de 
desconforto térmico na maior parte das horas do dia no período seco da região. Em estudos anteriores em Santarém Sousa et al. (2016) e Uchoa (2011) já evidenciaram a ocorrência de ilhas de calor na cidade, com temperaturas mais elevadas na região central da cidade (local de aglomerado urbanos, comercial e viário).

Assim, podemos evidenciar que as sensações térmicas ainda podem ser piores, visto que se espera que as variáveis climáticas, tais como temperatura, sejam maiores nestes locais. Vimos que as sensações de desconforto confirmadas por todos os índices analisados neste estudo podem ser agravadas quando associadas às atividades humanas em ambientes abertos, seja de trabalho, ou de lazer, podendo enfrentar cada vez mais desconforto térmico.

\section{CONCLUSÕES}

Os resultados apresentados demonstraram a influência da temperatura do ar, umidade relativa do ar, radiação solar e velocidade do vento na sensação de conforto térmico horário na cidade de Santarém (PA). Encontramos que no intervalo de $11 \mathrm{~h}$ as $18 \mathrm{~h}$ em ambiente aberto a sensação térmica varia de desconfortável a extremante desconfortável conforme o Índice de Temperatura e Umidade. Entre 14h e 17h, os índices apontam sensação muito quente com falha na termorregulação do corpo e cautela extrema, estas sensações térmicas estão associadas aos valores máximos de temperatura ar em torno de $31^{\circ} \mathrm{C}$ e umidade relativa inferior a $60 \%$.

Diante do exposto, faz-se importante o estudo sobre a sensação térmica de des(conforto) no período seco em Santarém (PA) para incentivar discussões acerca do assunto e evoluções na temática, para que haja maior difusão das condições atuais e debates acerca de ferramentas e mecanismo redutores de impacto causado pelo elevado índice de desconforto térmico, além de possibilitar a emissão de alertas nos horários mais críticos, além de evidenciar a necessidade de ilhas de frescor, tais como, a preservação dos igarapés urbanos que cortam a cidade e manutenção de praças, bosques e arborização para um equilíbrio do microclima urbano.

\section{REFERÊNCIAS}

ALMEIDA, E. M. A.. A configuração urbana e sua configuração com os microclimas: estudo de frações urbanas na cidade de Maceió. Dissertação (Mestrado) Universidade Federal de Alagoas, Maceió, 2006

AMORIM, M. C. C. T.. Ilhas de Calor em Birigui/SP. Revista Brasileira de Climatologia, v.1, n.1, 2005.

BARBOSA, P. H. D.; COSTA, A. C. L.; CUNHA, A. C.; JUNIOR, J. D. A. S.. Variabilidade de elementos meteorológicos e de conforto térmico em diferentes ambientes na Amazônia Brasileira. Revista Brasileira de Climatologia, v.2, n.17, 2015.

BARBOSA, P. H. D.; COSTA, A. C. L.; CUNHA, A. C.; SILVA JÚNIOR, J. A.. Variabilidade de elementos meteorológicos e de conforto térmico em diferentes ambientes na Amazônia Brasileira. Revista Brasileira de Climatologia, v.17, n.1, p.98118, 2015.
COSTA, A. C. L.; SILVA JÚNIOR, J. A.; CUNHA, A. C.; FEITOSA, J. R. P.; PORTELA, B. T. T.; SILVA, G. G. C.; COSTA, R. F.. Índices de conforto térmico e suas variações sazonais em cidades de diferentes dimensões na Região Amazônica. Revista Brasileira de Geografia Física, v.6, n.3, p. 478-487, 2013.

COSTA, A. C. L.; SILVA JÚNIOR, J. A.; CUNHA, A. C.; FEITOSA, J. R. P.; PORTELA, B. T. T.; SILVA, G. G. C.; COSTA, R. F.. Índices de conforto térmico e suas variações sazonais em cidades de diferentes dimensões na Região Amazônica. Revista Brasileira de Geografia Física, v.6, n.3, p.478-487, 2013.

COSTA, A. C.; RODRIGUES, H. J. B.; COSTA, J. L. O.; SOUZA, P. F. S.; SILVA JÚNIOR, J. A.; FEITOSA, A. C. L.. Variações termohigrométricas e estudo de Ilha de Calor Urbana na cidade de Bragança-PA e circunvizinhança. Revista Brasileira de Geografia Física, v.9, n.2, p.571-584, 2016. 
DINIZ JÚNIOR, J.; COSTA, A. C. L.; SANTOS, M. R. P.; VIEIRA, L. C. R.; OLIVEIRA, A. A. R.; OLIVEIRA, L. L.. Influência da vegetação nos parâmetros micrometeorológicos da área urbana em uma cidade de médio porte da Amazônia. Ciência e Natura, v.8, p.264-267, 2013.

DUARTE, D. H. S.; SERRA, G. G.. Padrões de ocupação do solo e microclimas urbanos na região de clima tropical continental brasileira: correlações e proposta de um indicador. Ambiente Construído, v.3, n.2 p.7-20, 2003.

FROTA, A. B.; SCHIFFER, S. L.. Manual de conforto térmico. 5 ed. São Paulo: Estúdio Nobel, 2001.

GARTLAND, L.. Ilhas de calor: Como mitigar zonas de calor em áreas urbanas. São Paulo: Oficina de textos, 2011.

MEMON, R. A.; LEUNG, D. Y. C.; CHUNHO, L. A.. A review on the generation, determination and mitigation of Urban Heat Island. Journal of Environmental Sciences, v.20, n.1, p.120128, 2008.

NECHET, D.; CUTRIM, E.; SOUZA, D. C.; SOUZA, P. F. S.. Variação diurna de eventos de trovoadas em Santarém-PA. In: CONGRESSO BRASILEIRO DE METEOROLOGIA, 14. Anais. Florianópolis: 2006.

NOBREGA, R. S.; LEMOS, V. S.. O microclima e o desconforto térmico em ambientes abertos na cidade do Recife-PE. Revista de Geografia, v.28, n.1, 2011.
OLIVEIRA, S.; ANDRADE, H.; VAZ, T.. The cooling effect of green spaces as a contribution to the mitigation of urban heat: a case study in Lisbon. Building and Environment, v.46, n.11, p.2186-2194, 2011.

RIZWAN, A. M.; LEUNG Y. D.; CHUNHO, L. I. U.. A review on the generation, determination and mitigation of Urban Heat Island. Journal of Environmental Sciences, v.20, n.1, p.120128, 2008.

SILVA JÚNIOR, J. A.. Estudo do Conforto Térmico e o Fenômeno da ilha de calor na cidade de Belém-PA durante o ano de 2010. In: SIMPÓSIO INTERNACIONAL DE CLIMATOLOGIA, 4. Anais. João Pessoa: 2011.

SOUSA, C.; OLIVEIRA, L. L.. Avaliação termo-higrométrica e do conforto térmico da cidade de Santarém-PA. In: SEMINÁRIO DE INICIAÇÃO CIENTÍFICA, 6. Anais. Santarém: 2016.

SOUSA, D. M.; NERY, J. T.. O conforto térmico na perspectiva da Climatologia Geográfica. Geografia, Londrina, v.21, n.2, p.65-83, 2012.

UCHÔA, P. W. S.. Estudo de variações termo-higrométricas de cidade equatorial devido ao processo de urbanização: o caso de Santarém-PA. Dissertação (Mestrado) Universidade Federal do Oeste do Pará, Santarém, 2011.

A CBPC - Companhia Brasileira de Produção Científica (CNPJ: 11.221.422/0001-03) detém os direitos materiais desta publicação. Os direitos referem-se à publicação do trabalho em qualquer parte do mundo, incluindo os direitos às renovações, expansões e disseminações da contribuição, bem como outros direitos subsidiários. Todos os trabalhos publicados eletronicamente poderão posteriormente ser publicados em coletâneas impressas sob coordenação da Sustenere Publishing, da Companhia Brasileira de Produção Científica e seus parceiros autorizados. Os (as) autores (as) preservam os direitos autorais, mas não têm permissão para a publicação da contribuição em outro meio, impresso ou digital, em português ou em tradução. 